\title{
Superior Surface of the Liver
}

National Cancer Institute

\section{Source}

National Cancer Institute. Superior Surface of the Liver. NCI Thesaurus. Code C33697.

The superior aspect of the liver. 